\title{
Localisation and distribution of $O$-acetylated $N$-acetylneuraminic acids, the endogenous substrates of the hemagglutinin-esterases of murine coronaviruses, in mouse tissue
}

\author{
Andreas Rinninger • Colette Richet · Alexandre Pons • \\ Guido Kohla • Roland Schauer • \\ Hans-Christian Bauer · Jean-Pierre Zanetta • \\ Reinhard Vlasak
}

(C) Springer Science + Business Media, LLC 2006

\begin{abstract}
Infections by mouse hepatitis viruses result in disease of the liver, the gastrointestinal tract, respiratory tract, and the central nervous system. Coronaviruses related to mouse hepatitis virus express a hemagglutinin-esterase surface glycoprotein, which specifically hydrolyses either 5$\mathrm{N}$-acetyl-4-O-acetyl neuraminic acid $\left(\mathrm{Neu} 4,5 \mathrm{Ac}_{2}\right)$ or $5-\mathrm{N}$ acetyl-9-O-acetyl neuraminic acid ( $\left.\mathrm{Neu} 5,9 \mathrm{Ac}_{2}\right)$. Moreover, these sialic acids represent potential cellular receptor determinants for murine coronaviruses. Until now, the distribution of these sialic acids in mouse brain was not thoroughly investigated. Particularly $\mathrm{Neu} 4,5 \mathrm{Ac}_{2}$ was not yet found in mouse brain. Using a sensitive method of gas chromatography coupled to mass spectrometry in the electron impact mode of ionization this manuscript demonstrates the occurrence of 13 different sialic acids varying in their alkyl and acyl substituents in mouse tissues including 5- $N$-acetyl-4- $O$-acetyl9- $O$-lactyl-neuraminic acid (Neu4,5 $\left.\mathrm{Ac}_{2} 9 \mathrm{Lt}\right), 5-\mathrm{N}$-acetyl-9-
\end{abstract}

A. Rinninger $\cdot$ H.-C. Bauer $\cdot$ R. Vlasak $(\triangle)$

Applied Biotechnology, Departments of Cell Biology and

Organismic Biology, University Salzburg, A-5020 Salzburg,

Austria

e-mail: rvlasak@applied-biotech.at

Tel: (43)-662-8044-7330

Fax: (43)-662-8044-168

C. Richet

Inserm U560, Place de Verdun, 59045 Lille Cedex

A. Pons - J.-P. Zanetta

CNRS Unité Mixte de Recherche 8576, Laboratoire de

Glycobiologie Structurale et Fonctionnelle, Université des

Sciences et Technologies de Lille, Bâtiment C9, 59655 Villeneuve

d'Ascq Cedex (France)

G. Kohla $\cdot$ R. Schauer

Biochemisches Institut, Christian-Albrechts-Universität zu Kiel,

Olshausenstr. 40, D-24098 Kiel, Germany
$O$-lactyl-neuraminic acid (Neu5Ac9Lt), 5- $\mathrm{N}$-acetyl-8- $O$ methyl-neuraminic acid (Neu5Ac8Me) and the 1,7-lactone (Neu5Ac1,7L) of neuraminic acid. $\mathrm{Neu} 4,5 \mathrm{Ac}_{2}$, relatively abundant in the gut, was present as a minor compound in all tissues, including liver, olfactory lobe, telencephalon, metencephalon and hippocampus. $\mathrm{Neu} 5,9 \mathrm{Ac}_{2}$ was also found in these tissues, except in the liver. It is suggested that these sialic acids represent the endogenous substrate and receptor determinants for murine coronaviruses.

Keywords Gas chromatography · Mass-spectrometry · Mouse hepatitis virus - Mouse tissues . 5- $N$-acetyl-4- $O$-acetylneuraminic acid · Sialic acid

$\begin{array}{ll}\begin{array}{l}\text { Abbreviations } \\ \text { amu }\end{array} & \text { atomic mass unit } \\ \text { EI } & \text { electron impact ionization } \\ \text { GC } & \text { gas chromatography } \\ \text { MS } & \text { mass-spectrometry } \\ \text { HFB } & \text { heptafluorobutyrate } \\ \text { HFBAA } & \text { heptafluorobutyricacid anhydride } \\ \text { Kdn } & \text { 3-deoxy-D-glycero-D-galacto- } \\ & \text { nonulosonic acid; } \\ & \text { the nomenclature of the other sialic acids is } \\ & \text { after Schauer and Kamerling [36] } \\ \text { TIC } & \text { total ion count } \\ \text { HE } & \text { hemagglutinin esterase } \\ \text { MHV } & \text { mouse hepatitis virus }\end{array}$

\section{Introduction}

Viral infections are initiated by binding of the virus to cellular receptors. In many instances the virus-receptor recognition is highly specific, conferring species specificity and/or 
tissue specificity. Coronaviruses, which belong to the order of Nidovirales, infect different animal species. They are enveloped viruses with a single-stranded plus-sense RNA genome of approximately 30 kilobases. Their genome is characterized by a $5^{\prime}$-terminal cap structure and a $3^{\prime}$ poly A tract. The coronaviridae are divided into the toroviruses and the coronaviruses. The coronavirus genus is divided into three serogroups [1]. Most recently novel human coronaviruses were identified during the search on the etiological agent causing Severe Acute Respiratory Syndrome (SARS) [2-5]. SARS-CoV is an early split off of group 2 coronaviruses [6], HCoV-NL63 belongs to group 1 [7], and CoV-HKU I is a group 2 coronavirus [8]. Mouse hepatitis viruses (MHV) belong to group 2, together with rat coronaviruses, puffinosis coronavirus, human coronavirus OC43 ( $\mathrm{HCoV} \mathrm{OC} 43)$, bovine coronavirus $(\mathrm{BCoV})$, and porcine hemagglutinating encephalomyelitis virus (HEV). A major characteristic of group 2 coronaviruses is the presence of a hemagglutinin-esterase (HE) surface glycoprotein in addition to the viral spike protein. It was previously demonstrated [9] that the HE protein of the MHV strain $S$ is a sialate-4- $O$ acetylesterase, which is able to de- $O$-acetylate $\mathrm{Neu} 4,5 \mathrm{Ac}_{2}$. In addition to this strain, puffinosis coronavirus and sialodacryoadenitis virus exhibit a similar substrate specificity [10-12]. The HE proteins of group 2 coronaviruses interact either with $\mathrm{Neu} 4,5 \mathrm{Ac}_{2}$ or sialic acids with $O$-acetylation at position $9\left(\mathrm{Neu} 5,9 \mathrm{Ac}_{2}\right)$. While human coronaviruses related to the reference strain $\mathrm{HCoV} \mathrm{OC} 43$ and $\mathrm{BCoV}$ specifically interact with $\mathrm{Neu} 5,9 \mathrm{Ac}_{2}$ via the $\mathrm{HE}[13,14]$ and the spike glycoprotein [15], the murine coronavirus strains $S$ and JHM recognize $\mathrm{Neu} 4,5 \mathrm{Ac}_{2}$ [9] and a cellular glycoprotein termed MHV-receptor or CEACAM 1a [16-19]. For Influenza $C$ viruses and $\mathrm{BCoV}$ it was shown that they utilize Neu5,9 $\mathrm{Ac}_{2}$ as receptor determinant, which may be part of glycoproteins or the sialic-acid-containing gangliosides [14,20]. Although it is known that MHV-like coronaviruses bind and hydrolyse either Neu4,5 $\mathrm{Ac}_{2}$ or Neu5,9 $\mathrm{Ac}_{2}[9,21]$, the significance for infections by murine coronaviruses remained unclear.

$\mathrm{Neu} 4,5 \mathrm{Ac}_{2}$ is known to be expressed to high levels in guinea pigs and horses [22] as well as in a few other animals [23]. No detailed analysis of the occurrence of this sialic acid in mice is available. Recently, $\mathrm{Neu} 4,5 \mathrm{Ac}_{2}$ was detected in the colon and trachea of mice, although sialic acids $O$-acetylated at the glycerol side-chain prevailed [24]. MHV strains exhibit different virulence and tissue tropisms. MHV strains JHM and $S$ represent neurotropic viruses, which cause either chronic demyelinating disease or rapidly fatal infection of the CNS, associated with a virus dissemination to the liver, bowel and other organs $[25,26]$. MHV strain A59 produces a mild to moderate meningoencephalitis and chronic demyelination, as well as moderate to severe hepatitis $[27,28]$. Enterotropic MHV strains preferentially replicate in the intestinal mucosa [29]. Since different strains of MHV preferentially infect ei- ther the gastrointestinal tract, the liver, the respiratory tract or the CNS, we were aiming to analyse the distribution of $O$-acetylated sialic acids in all mouse tissues susceptible for infection by MHV.

A method was developed for the identification and quantification of the sialic acid diversity [30]. It involved, after liberation of sialic acids using mild acid hydrolysis, the formation of methyl esters with diazomethane, followed by the blockage of all free hydroxyl-(amino-) groups with heptafluorobutyric acid anhydride. Subsequent GC/MS analysis of these volatile derivatives allowed, in the electron impact mode of ionization, to identify 38 different sialic acids in samples from different origins. This method was applied to the study of the sialic acids glycosidically bound to glycoproteins and glycolipids from human erythrocyte membranes [31]. It allowed the unambiguous identification and quantification of a large variety of sialic acids including $\mathrm{Neu} 4,5 \mathrm{Ac}_{2}$, which was never detected before in human tissues. The same methodology was used to demonstrate an increasing gradient of $O$-acetylation in the descending human gut [32]. Because of its sensitivity it became possible to analyze the occurrence and distribution of $\mathrm{Neu} 4,5 \mathrm{Ac}_{2}$ in less than $1 \mathrm{mg}$ of initial total homogenate from different mouse tissues.

This study clearly demonstrates the presence of this sialic acid in mice and discusses the implications of tissue- and development-specific variations of the different sialic acids.

\section{Materials and methods}

Chemicals and media

Diazogen $^{\mathrm{TM}}$ was from Aldrich (Milwaukee, USA). Heptafluorobutyric acid anhydride (HFBAA; puriss) was from Fluka (Buchs, Switzerland). Heavy walled screw cap tubes $(10 \times 100 \mathrm{~mm})$ and Teflon-lined caps (GL14) were from Schott (Mainz, Germany). Diazomethane was prepared in a Wheaton ${ }^{\mathrm{TM}}$ apparatus according to the procedure proposed by the manufacturer and the diazomethane solution was kept as aliquots in tubes identical to the reaction vials at room temperature in a ventilated hood.

\section{Animals}

For all our studies we used NMRI (Naval Medical Research Institute, USA) mice.

Preparation of primary astrocytes cell culture

Astrocytes were isolated and derived from newborn (NMRI) mouse brain as described by Tontsch and Bauer [33]. Brain halves were dissected under sterile conditions. Meninges were carefully removed, the tissue minced in cold DiSG solution containing $10 \mathrm{mM}$ HEPES, $17 \mathrm{mM}$ glucose and 
$22 \mathrm{mM}$ sucrose $(\mathrm{pH}$ 6.8) and dissociated in $2 \mathrm{ml} 0.3 \%$ Trypsin/DiSG for $5-10 \mathrm{~min}$. Then $7 \mathrm{ml}$ warm astrocyte medium was added, and the tissue fragments were dissociated by trituration through a Pasteur pipette. The cells were resolved in $8 \mathrm{ml}$ astrocytes medium and equally plated in four $25 \mathrm{~cm}^{2}$ flasks (Greiner, Austria). Astrocyte medium was Dulbecco's Modified Eagle's Medium (DMEM) purchased from Gibco with glucose $(6 \mathrm{~g} / \mathrm{l})$ containing $10 \%$ FCS and supplemented with penicillin $(50 \mathrm{IU} / \mathrm{ml})$ and streptomycin $(50 \mu \mathrm{g} / \mathrm{ml})$. The astrocytes were incubated at $37^{\circ} \mathrm{C}$ in a humidified atmosphere of $5 \% \mathrm{CO}_{2}$ in air. After $6 \mathrm{~h}$, medium was partly aspirated to remove floating cells and neurons and changed to fresh astrocytes medium. Cells were cultured for 12 days to confluency with regular changes of the culture medium every third day.

Astrocytes were harvested with a sterile cell scraper, washed 5 times in warm $1 \times$ PBS and centrifuged at $300 \mathrm{~g}$ for $10 \mathrm{~min}$. Supernatant was aspirated and the weight of the cell pellet was determined.

Dissection and delipidation of mouse tissues

Pre- and perinatal mice were sacrificed by decapitation, adult mice by cervical dislocation. After dissection, the brains were washed in cold $1 \times$ PBS and the meninges were removed. Brains were from embryos at stage 13 (E13), 15 (E15), 17 (E17), from newborn (P0), postnatal day 7 (P7) and adult. The wet weight of each sample was determined. The hippocampus, olfactory lobe, metencephalon and the telencephalon (Figure 1) as well as liver and gut (duodenum, jejunum, ileum, cecum, colon and rectum) were prepared from an adult, male NMRI mouse.

Mouse tissues were minced in cold methanol, homogenized and samples containing $10 \mathrm{mg}$ wet weight of the initial tissue were taken for delipidation. Cold $\mathrm{MeOH}$ was added to the homogenized tissue samples to a final volume of $1 \mathrm{ml}$ and transferred into glass screw top vials. After stirring the samples for $15 \mathrm{~min}, 500 \mu \mathrm{l}$ chloroform was added to each vial. To separate the glycoproteins and glycolipids, the samples were stirred for another $30 \mathrm{~min}$ and centrifuged at $3600 \mathrm{~g}$ for $10 \mathrm{~min}$ at room temperature. The supernatants, containing the glycolipids, were transferred into new glass vials. Pellets were resolved in $1 \mathrm{ml}$ chloroform/methanol $(2: 1 \mathrm{v} / \mathrm{v})$, stirred for $60 \mathrm{~min}$ and centrifuged at $3600 \mathrm{~g}$ for $10 \mathrm{~min}$ at room temperature. The combined supernatants (glycolipids) and pellet (glycoproteins) were dried separately under a light stream of nitrogen. The tissue samples were then ready for GC/MS analysis.

GC/MS analysis of sialic acid from mouse tissue

The GC/MS analysis of sialic acid was performed essentially as previously described [30] with a few modifications
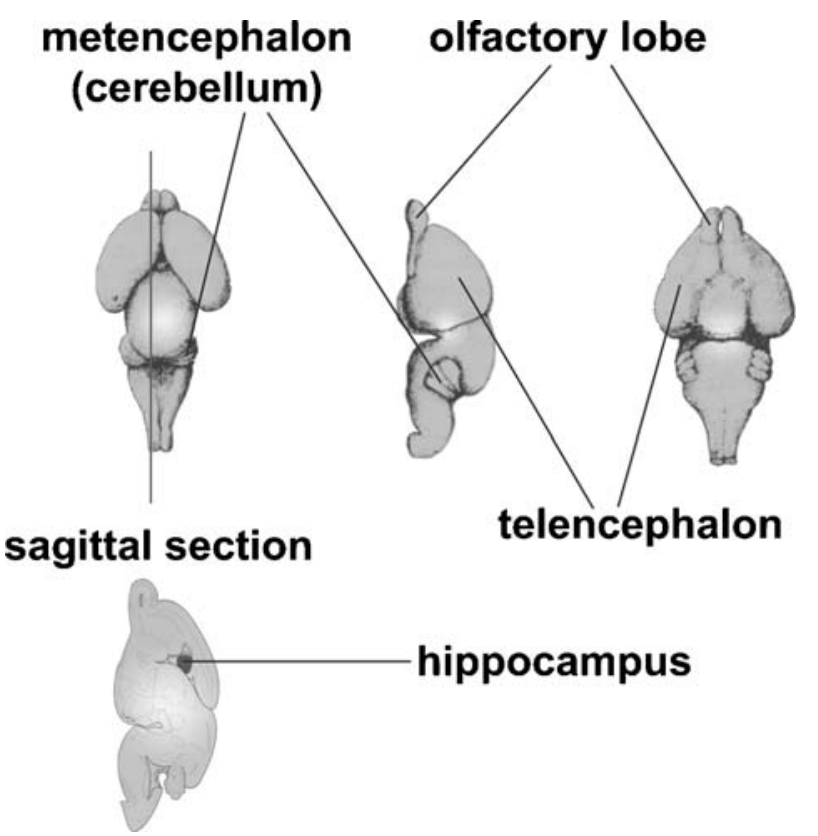

Fig. 1 Brain sections. Sections were taken from an adult NMRI mouse. For the preparation of the hippocampus a sagital section was taken as indicated.

as follows. The dried samples were submitted to mild acid hydrolysis $\left(2 \mathrm{M}\right.$ acetic acid for $105 \mathrm{~min}$ at $80^{\circ} \mathrm{C}$ ) with intermittent agitation during the first $15 \mathrm{~min}$ of the reaction. The lipid samples were then lyophilized to dryness. The protein/glycoprotein samples were centrifuged for $60 \mathrm{~min}$ at $4{ }^{\circ} \mathrm{C}$ $(60 \mathrm{~min}$ at $3000 \mathrm{rpm})$ and the supernatant transferred to reaction vials, followed by lyophilisation.

All samples were methyl-esterified with diazomethane. Briefly, samples were supplemented with $200 \mu$ l of anhydrous redistilled methanol, then $200 \mu \mathrm{l}$ of the diazomethane reagent was added in a ventilated hood. The samples were left in this reagent until analysis. Before GC/MS analysis, the samples were dried under a stream of nitrogen in a ventilated hood, and then supplemented with $400 \mu \mathrm{l}$ of acetonitrile and $50 \mu \mathrm{l}$ of heptafluorobutyric acid anhydride (Fluka). After heating for $5 \mathrm{~min}$ at $150^{\circ} \mathrm{C}$, samples were evaporated in a stream of nitrogen until dryness, and then taken up in the desired volume of acetonitrile, which had been kept dry on calcinated calcium chloride. The samples $(1 \mu \mathrm{l})$ were directly injected on the Ross injector of the GC/MS apparatus and analyzed in the impact mode of ionization.

The GC separation was performed on a Carlo Erba GC 8000 gas chromatograph equipped with a $25 \mathrm{~m} \times 0.32 \mathrm{~mm}$ CP-Sil5 CB Low bleed/MS capillary column, $0.25 \mu \mathrm{m}$ film phase (Chrompack France, Les Ullis, France). The temperature of the Ross injector was $260^{\circ} \mathrm{C}$ and the samples were analyzed using the following temperature program: $90^{\circ} \mathrm{C}$ for $3 \mathrm{~min}$ and then $5^{\circ} \mathrm{C} / \mathrm{min}$ until $260^{\circ} \mathrm{C}$. The column was coupled to a Finnigan Automass II mass spectrometer (mass detection limit 1000). The analyses were 
performed in the electron impact mode (ionization energy $70 \mathrm{eV}$; source temperature $150^{\circ} \mathrm{C}$ ). In order to preserve the filament of the ionization source, the GC/MS records were performed $5 \mathrm{~min}$ after the injection of the sample. For quantitations, the chromatograms were analyzed using the Xcalibur software (Thermoquest-Finnigan) integrating the signals at $m / z=169$, a reporter base ion specific for heptafluorobutyrate (HFB) derivatives. This procedure allows overcoming the problem of contaminations by derivatives unrelated to sialic acids present in the samples derived from total homogenates. Each constituent was identified through its retention time and fragmentation profile. The major contamination interferences observed with the analysis of sialic acids were due to disaccharides of hexoses which were particularly abundant in the material derived from the liver lipid fraction.

\section{Results}

Identification and quantification of sialic acids

The GC/MS analysis of sialic acids as HFB derivatives allows separation of the different sialic acids, which are identified by their retention times and fragmentation patterns in the electron impact mode of ionization starting from very small amounts of total homogenates. Indeed, quantities as low as $1 \mathrm{pg}$ of each sialic acid can be unambiguously identified with the MS detector through specific fragmentation mass spectra [30].

In the different mouse samples, 13 different sialic acids were identified and shown to be present at various levels (Tables 1 and 2). Six different mono- $O$ acylated sialic acids were detected, including 5- $N$-acetyl4- $O$-acetyl neuraminic acid $\left(\mathrm{Neu} 4,5 \mathrm{Ac}_{2}\right), 5-\mathrm{N}$-acetyl-7- $\mathrm{O}$ acetyl neuraminic acid (Neu5,7 $\left.\mathrm{Ac}_{2}\right), 5-\mathrm{N}$-acetyl-9-O-acetyl neuraminic acid (Neu5,9 $\mathrm{Ac}_{2}$ ), 5- $\mathrm{N}$-acetyl-9-O-lactyl neuraminic acid (Neu5Ac9Lt), 5- $\mathrm{N}$-glycolyl-9- $O$-lactyl neuraminic acid (Neu5Gc9Lt) and 5- $N$-acetyl-8- $O$-sulfo neuraminic acid (Neu5Ac8S). Besides 5- $\mathrm{N}$-acetyl neuraminic acid (Neu5Ac), generally present as the major sialic acid, traces of 2-keto-3-deoxynononic acid (Kdn) were detected as a minor compound in the glycoproteins of the gut and in the glycolipids of the liver. A single di- $O$-acylated sialic acid was detected as 5- $\mathrm{N}$-acetyl-4-O-acetyl-9-O-lactyl neuraminic acid (Neu4,5 $\left.\mathrm{Ac}_{2} 9 \mathrm{Lt}\right)$. Two compounds of the 5- $\mathrm{N}$ glycolyl neuraminic acid (Neu5Gc) family, Neu5Gc and its lactylated derivative Neu5Gc9Lt were especially abundant in the glycoproteins and glycolipids of the liver. 5- $\mathrm{N}$-acetyl8-O-methyl neuraminic acid (Neu5Ac8Me) and neuraminic acid (Neu) were also present, the latter especially in the glycolipid fraction from various tissues. The intra-molecular lactone of Neu5Ac (Neu5Ac1,7L) was particularly abundant in the glycolipids of the mesencephalon (more than 90\%) and of the brain at $\mathrm{P} 7$.

Sialic acids in different mice tissues

Neu4,5 $\mathrm{Ac}_{2}$ was abundant in glycoproteins $(16 \%)$ and glycolipids (27.4\%) of the gut (Tables 1 and 2). This finding correlates with data obtained by LC/MS analysis, when Morimoto et al. observed that $15.8 \%$ of the total peak area of sialic acids in the mouse colon represent this neuraminic acid derivative [24]. Smaller, but significant levels of Neu4,5 $\mathrm{Ac}_{2}$ were present in glycoproteins of the olfactory lobe, metencephalon and telencephalon. Remarkably, in the glycolipid fraction the relative amount of this sialic acid was lower in the neuronal tissues. In the gut, $\mathrm{Neu} 4,5 \mathrm{Ac}_{2}$ represented $27.4 \%$ of the total sialic acids in the glycolipid fraction, compared to $16 \%$ in the glycoprotein fraction. In almost all tissues examined, Neu5Ac and its derivatives were the major sialic acids with the exception of the glycolipid fraction of the adult metencephalon and the P7 brain in which Neu5Ac1,7L was the major compound (Table 2). Neu5Gc and its lactylated derivative Neu5Gc9Lt were especially abundant in the glycoproteins and glycolipids of liver (about $70 \%$ of total sialic acids). In contrast, Neu5Gc and Neu5Gc9Lt were poorly expressed in adult brain (Tables 1 and 2). Significant amounts of Neu5Ac8Me (7.3 and 12.8\%) were observed with a particular abundance in gut glycoproteins and glycolipids (Tables 1 and 2). Neu was particularly abundant in the olfactory lobe and in the gut glycolipids (Table 2). Indirect evidence for the presence of this compound in $\mathrm{a} \mathrm{GD}_{3}$ ganglioside isolated from human melanoma was previously forwarded [34].

Distribution of sialic acids during mouse brain development

As shown in Table 1, the different glycoprotein-bound sialic acids showed variable patterns during total brain development. Glycolipid-bound Neu4,5 $\mathrm{Ac}_{2}$ was only detectable in newborn mouse brain (P0) and seven day old mice (P7), whereas the glycoprotein-bound form was present during all stages of the brain development. The other mono- $O$ acetylated sialic acids $\left(\mathrm{Neu} 5,7 \mathrm{Ac}_{2}\right.$ and $\mathrm{Neu} 5,9 \mathrm{Ac}_{2}$ ) also showed significant quantities of their glycolipid bound forms at P0 (Tables 1 and 2).

Neu5Ac was found in very high amounts (60-98\%) in almost all stages of the developing brain, except the glycolipids of P7 brain. Here, we found high amounts (57.7\%) of the 1,7 lactone of Neu5Ac and significant amounts of Neu (19.3\%). Glycolipid-bound Neu5Gc was only verifiable in the embryonic stages E15 and E17 of the mouse brain, whereas glycoprotein-bound Neu5Gc decreased till day of birth and then increased again. Neu5Ac8Me and Neu5Ac9Lt showed a maximal expression at birth, while $\mathrm{Neu} 4,5 \mathrm{Ac}_{2} 9 \mathrm{Lt}$ showed 


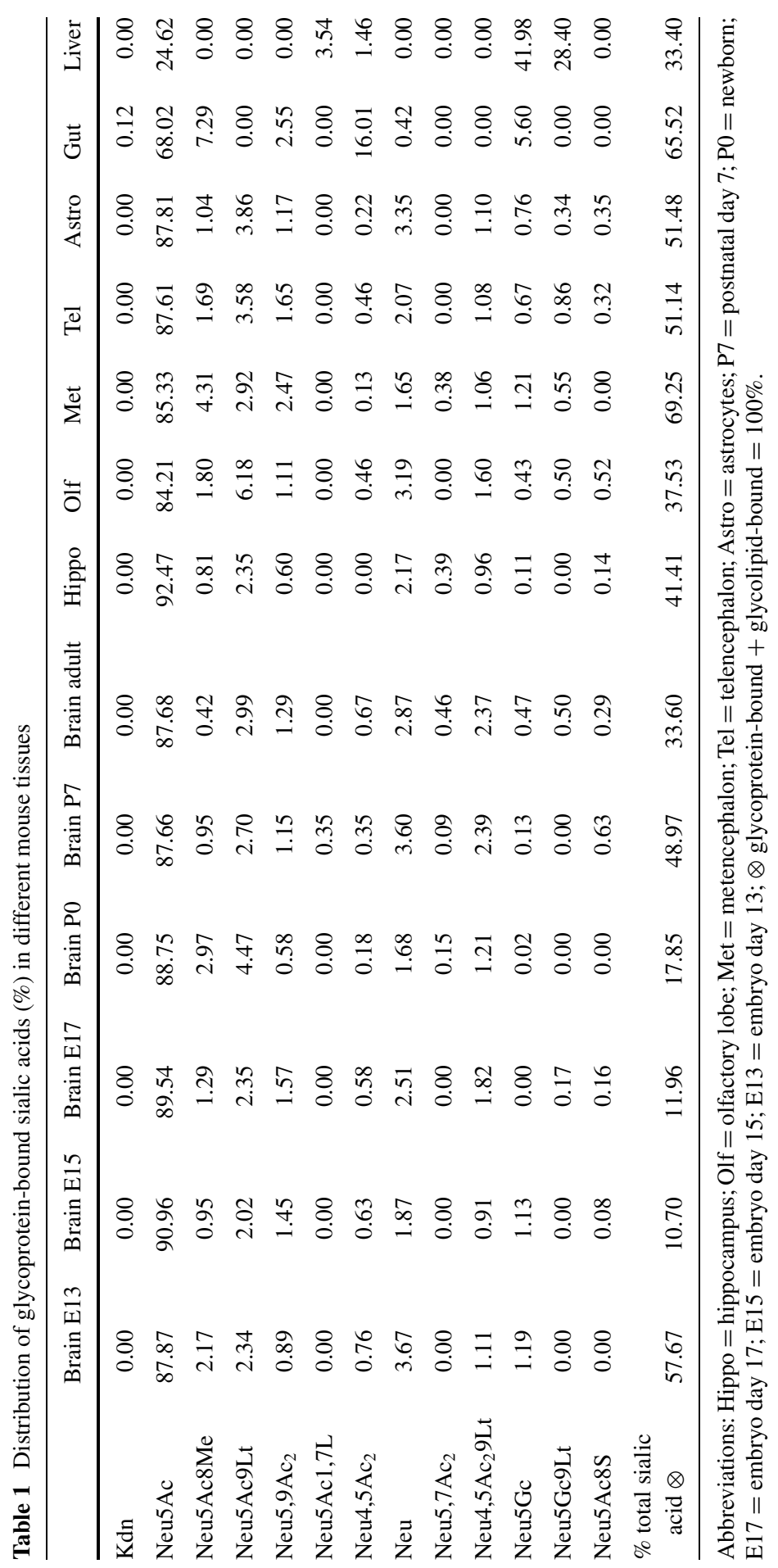




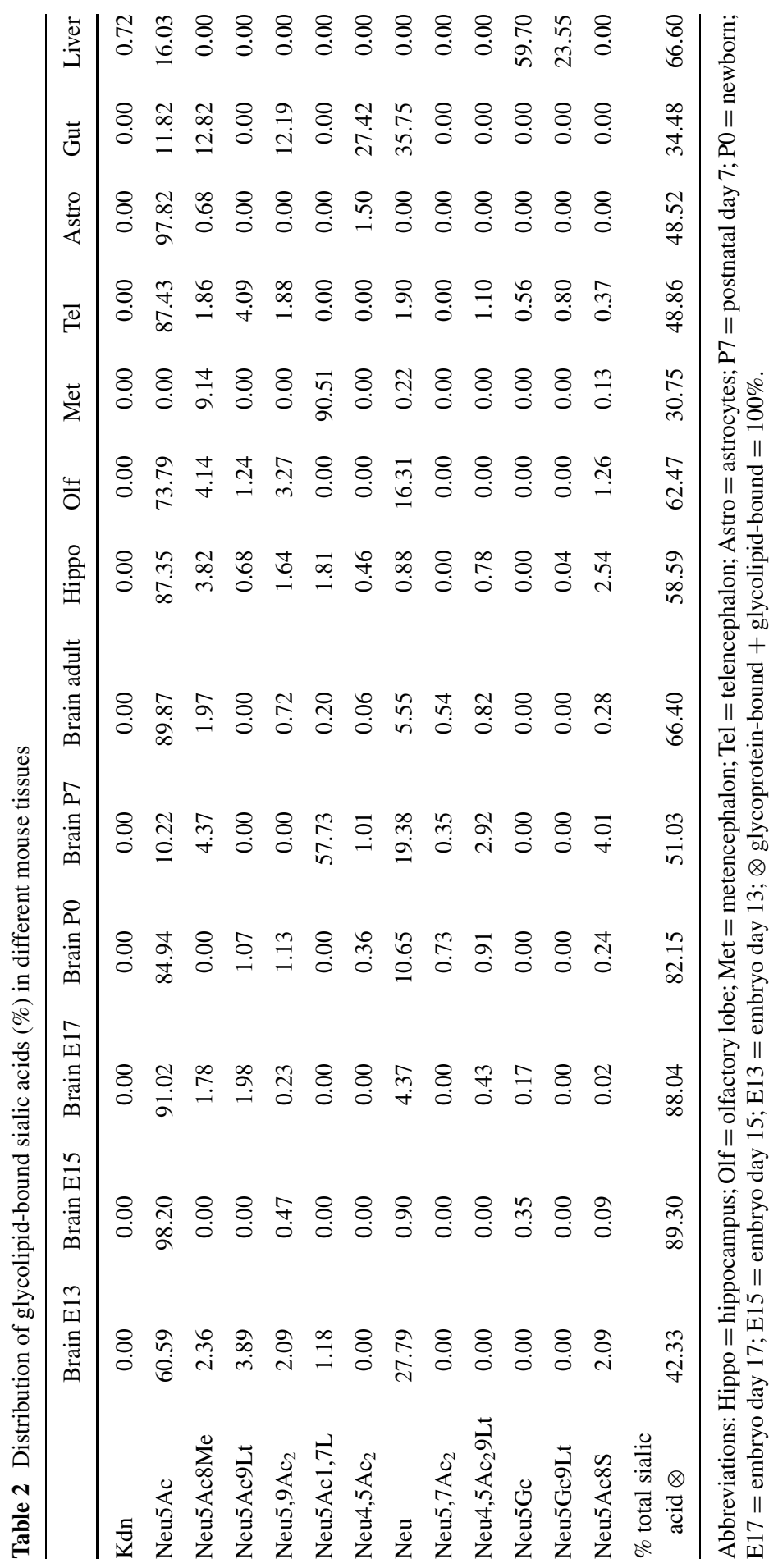


a lower relative abundance at the same period. A similar pattern was also observed for Neu5Gc9Lt and Neu5Ac8S.

\section{Discussion}

Due to methods used in the past, the analysis of $O$-acetylated sialic acids in glycoconjugates was difficult. The first structural analysis of various sialic acids, especially $O$-acetylated ones by mass-spectrometry, was reported by Kamerling et al. [35], using pertrimethylsilyl derivatives of the sialic acid methyl esters. This method significantly contributed to the discovery of a series of previously unknown naturally occurring sialic acids [36]. The GC/MS method used in this report differed essentially from other methodologies using HPLC separation of fluorescent compounds $[22,37,38]$ for which the retention time is the major criterion, the coupling with mass spectrometry being difficult. These techniques require an initial purification of the liberated sialic acids, a timeconsuming step performed starting from much higher quantities of initial material (at least 3 orders of magnitude). Furthermore, due to the hydrolysis and isolation procedure, minor quantities of sialic acids may be lost. Even if pooled mice brain were used for the delipidation step (needed for having data on glycoprotein and glycolipid-bound sialic acids), all data presented here were obtained on samples corresponding to $1 \mathrm{mg}$ of initial protein or less.

The identity of the different compounds was ascertained by their fragmentation mass spectra and retention times. As previously described, the identification of the different sialic acids was performed using a chromatogram reconstitution for the ion at $m / z=169$ specific of HFB derivatives (Figure 2). This procedure allowed the elimination of the contaminants like glucose necessarily present in total homogenate samples. The manual integration of the areas of the different peaks allowed a quasi-perfect reproducibility for the major compounds (generally Neu5Ac; less than $0.001 \%$ of the reported values) and a good reproducibility for minor compounds (in all cases less than $1 \%$ of the reported values). Furthermore, the re-injection of a sample after the first analysis gave the same results within less than $1 \%$ error. The second step of identification was performed using chromatogram reconstitution with ions specific of the different classes of sialic acids $(\mathrm{m} / z=861$ for mono- $O$-acetylated sialic acids; $m / z=707$ for di- $O$-acetylated sialic acids; $m / z=227$ for Neu5Gc derivatives; $m / z=112$ for 9-O-lactylated sialic acids; $m / z=122$ for 8 - $O$-sulfated sialic acids; $m / z=805$ for 8-O-methyl sialic acids and $m / z=505$ for Neu). Finally, the exact position of the $O$-acetyl group of mono- $O$-acetyl sialic acids was determined by their precise fragmentation patterns [30].

Based on these criteria, the population of the sialic acids of mice tissues presents a high diversity. Although we did not analyze the mouse gut mucins in particular (homogenates contained the mucus as well as subjacent tissues) it should be emphasized that the sialic acid composition of the mouse gut glycoproteins is significantly different from the sialic acid composition of human gut mucins [32]. A characteristic of human gut is its high level of oligo- $O$-acetylation. In the mouse gut, we could not detect significant amounts of such sialic acid. Careful examinations of the GC/MS chromatogram indicated that these compounds were never present at a level 20 times lower than minor sialic acids observed in mouse gut i.e. Neu. Therefore these compounds, although detectable, were not considered.

In conclusion, the diversity of sialic acids is concerned with all investigated mouse tissues and was observed both in glycoproteins and in glycolipids.

$\mathrm{Neu} 4,5 \mathrm{Ac}_{2}$ has been detected for the first time in mouse brain and it was observed in all target tissues of MHV. We observed a complete absence of glycoprotein-bound $\mathrm{Neu} 4,5 \mathrm{Ac}_{2}$ in the hippocampus.

The occurrence of $O$-acetylated sialic acids in glycolipids has been documented in many publications $[39,40]$. Earlier identification of $O$-acylation in gangliosides was possible by using two-dimensional thin-layer chromatography with an intermediate step of exposure to ammonia vapors [41]. Nevertheless, this method does not allow the identification of the precise nature and position of $O$-acyl groups. The use of antibodies or lectins specific for 9- $O$-acetylated sialic acids in gangliosides allowed detection of these compounds $[42,43]$. In our analyses of mammalian tissues with the new GC/MS technique, 9-O-lactylated compounds are generally more abundant than $9-O$-acetylated sialic acids. This is the case for human [31,32], murine (here) and rat brain synaptosomal plasma membranes (Zanetta, unpublished results). The presence of $\mathrm{Neu} 4,5 \mathrm{Ac}_{2}$ is also a common feature in these three species, although the levels being lower compared to horse tissues $[36,44]$. However, as is best illustrated with the high level in the murine gut and the low level in the other mouse tissues, its expression apparently is tissue-specific. Therefore, the enzyme acetyl-CoA: Sialate-4- $O$-acetyltransferase (E.C. 2.3.1.44) involved in the synthesis of this compound should be present in these species and expressed in different activities $e$.g. in the various mouse tissues. This enzyme has recently been solubilized from guinea-pig liver Golgi membranes and partially characterized [45].

Studies on the sialic acids of the human erythrocyte membranes [31] emphasized the fact that individual variations are present for apparently healthy individuals. This was also observed for sialic acids from gut mucins [32], although an increasing gradient of $O$-acetylation in the descending gut was always observed. Evidently, the reasons for these individual variations remain speculative.

From the quantitative point of view, it is emphasized that the glycoprotein-bound level of sialic acids is low at the 
Fig. 2 GC/MS analysis of the sialic acids found in P7 mouse brain glycoprotein fraction. (a) Chromatogram obtained for the total ion count (TIC). (b) Chromatogram reconstitution for the ion at $m / z=169$ specific for HFB derivatives. (c) EI fragmentation mass spectrum of Neu4,5 $\mathrm{Ac}_{2}$. Note in (a) that only Neu5Ac can be safely detected on the TIC chromatogram. In (b), the different minor sialic acids can be extracted from the majority of the contaminants and can be safely analyzed. Neu4,5 $\mathrm{Ac}_{2}$ is easily identified through a series of reporter fragment ions at $m / z=861,704$ and 491

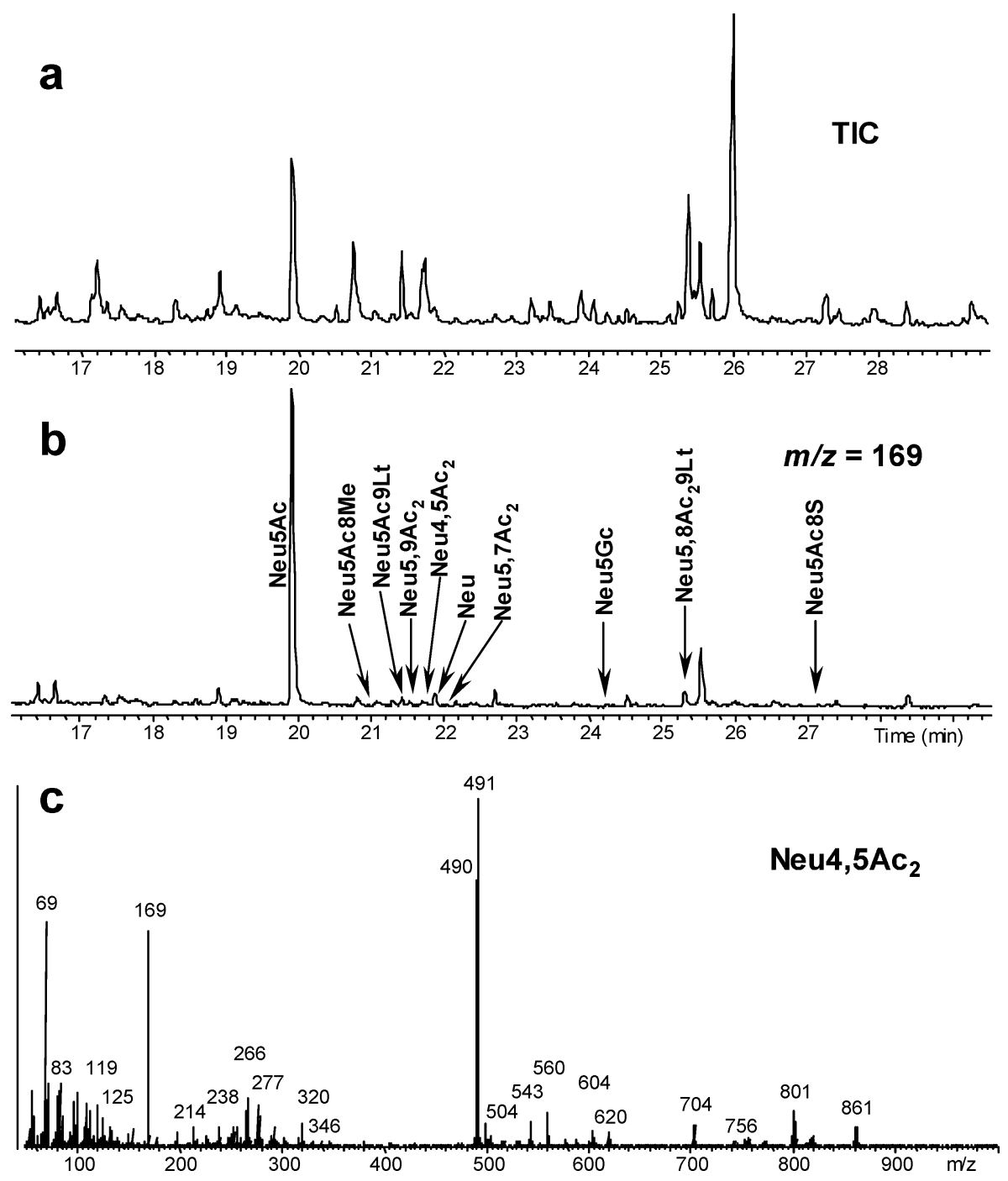

period between $\mathrm{E} 15$ and $\mathrm{P} 0$ in the mouse brain. In the case of $\mathrm{Neu} 4,5 \mathrm{Ac}_{2}$, the changes from $0.6 \%$ at $\mathrm{E} 17$ to $0.2 \%$ at $\mathrm{P} 0$ and to $0.7 \%$ in the adult is significant, especially considering the absolute amount of this compound in the samples. Analysis of sialic acids in cultures of pure astrocytes, which are susceptible to infection by MHV, also showed the presence of $\mathrm{Neu} 4,5 \mathrm{Ac}_{2}$ in these cells (Tables 1 and 2). The low amounts of $\mathrm{Neu} 4,5 \mathrm{Ac}_{2}$ in brain tissue raised the question of its cell localization. It may be specific for certain cell types but no evidence for this is provided in this study.

Studies of 9- $O$-acetylation showed a specific association of Neu5,9 $\mathrm{Ac}_{2}$ with synaptophysin [42]. This hypothesis may be verified using the $\mathrm{HE}$ protein as a lectin for detecting endogenous ligands and identification of these ligands using proteomic techniques.

The poor expression of Neu5Gc in the neuronal probes studied, in contrast to e.g. mouse liver, corresponds with similar observations made in other mammals [46]. It is discussed that this phenomenon is related to the function of the brain. A rare sialic acid is $8-O$-sulfated Neu5Ac, which was found in small to minor quantities in the neuronal probes investigated. Strikingly, it was absent both in glycoproteins and glycolipids from gut and liver. It was also described to occur, by using the same analytical method, in human erythrocytes [31]. By LCESI-MS, Morimoto et al. [24] identified Neu5Ac8S also in various tissues of mice and rats in relatively small quantities.

Another rare sialic acid, known to occur in relatively large amounts in some echinoderm species (reviewed in $[47,36]$ ) is 8-O-methylated Neu5Ac. Since the sialic acids were derivatised by diazomethane in the analytical method applied here, a mere chemical origin cannot be excluded. However, this is not very likely since the methyl group is exclusively found at $O-8$ and the amounts in the various mouse tissues differ, with both glycoproteins and glycolipids of the gut sharing a maximum of almost $13 \%$ Neu5Ac8Me. With regard to the finding of $\mathrm{Neu}$ (de- $N$-acetylated Neu5Ac) in most of the mouse tissues analyzed, this again, is possibly not due to an artefact. Neu has been discovered in various mammalian, 
including human cells like leucocytes, melanoma and neuroblastoma cells $[48,39]$. Data on the biosynthesis and regulation of Neu, which is believed to be involved in transmembrane signaling [49], are scarce. Manzi et al. [50] reported a rapid turnover rate of the $N$-acetyl groups in the sialic acid moiety of melanoma gangliosides as studied by radioactive labelling experiments. The occurence of Neu5Ac1,7L in sometimes large quantities in the brain and liver is particularly puzzling. This compound was never detected before the initial study [30], the major reason being that this compound was missed in all analyses involving ion-exchange purification of sialic acids before analysis. Furthermore, it does not react with fluorescent reagents specific for $\alpha$-ketocarboxylic acids and enables a sensitive HPLC analysis of sialic acids [37]. This substance is the only sialic acid being identified in the GC/MS analysis when the diazomethane methyl-esterification was omitted. Furthermore, this lactone having a pseudo-dioxane ring, is stable to acidic and alkaline treatments compared with other esters. It can be recovered partially after acid-catalysed methanolysis. The abundance of this compound in the glycolipid fraction of P7 contrasted with its quasi absence in all other glycoprotein and glycolipid fractions, except in liver glycoproteins. In the P7 glycolipids but not in the other tissues studied this abundance is associated with the abundance of Neu, as well as in other tissues with Neu5Ac1,7L occurrence (Tables 1 and 2). However, in the corresponding glycoprotein fraction of the same sample, the abundance of the lactone is not associated with the presence of Neu. It is emphasized that Neu5Ac1,7L was found to be the ligand of human IL-4 [51]. Although it is not known whether the murine IL-4 has the same lectin activity as the human one, it may be speculated that gangliosides possessing this type of sialic acid at this specific stage of development may be involved in signalling processes related to cell proliferation or apoptosis.

In summary, this manuscript provides the first evidence that many different sialic acids are present in mouse tissues. In fact, except the presence of Neu5Gc, it resembled that of human tissues in which the same mono- $O$-acylated compounds are present [31,32]. For instance Neu5,9 $\mathrm{Ac}_{2}$, the predominant mono- $O$-acetylated sialic acid in human gut is also present in the mouse gut, even though in much lower amounts. There are also noticeable differences. Neu5,7 $\mathrm{Ac}_{2}$ could only be detected in very low amounts in the mouse brain but not in the gut. Remarkably, Neu4,5 $\mathrm{Ac}_{2}$, is present at a high level in the gut, at lower but significant levels in glycoproteins of the liver and in glycoproteins and glycolipids of the brain, two tissues known to be targets of the mouse hepatitis virus strain $\mathrm{S}$. Di- and oligo- $O$-acetylated sialic acids could not be detected in any kind of mouse tissue tested.

In an investigation on the transneural spread of the neurotropic MHV strain JHM within the mouse brain, Barnett et al. found that MHV JHM spreads in a characteristic way throughout the rodent CNS without infection of the hippocampal complex [52]. Several lines of evidence suggest that the presence of CEACAM1 is required for infection by murine coronaviruses. CEACAM1 is a member of the immunoglobulin family, which is involved in intercellular adhesion and angiogenesis. The isoform CEACAM1a is also involved in binding and penetration of murine coronaviruses. The presence of this molecule is apparently essential for infection in vivo: Ceacam1a-/- mice are resistant to infection by MHV strain A59 [53]. CEACAM1a is a highly glycosylated surface protein [18], which is present in apical membranes of many epithelial cells [54]. In the case of MHV strain A59, which does not express an HE protein, binding is mediated by the viral spike protein $S$. The binding site is located at the aminoterminal region of the $\mathrm{S}$ protein, which recognizes the first loop of CEACAM1. During biosynthesis and maturation, the $\mathrm{S}$ protein is proteolytically hydrolyzed in the Golgi into the subunits S1 and S2, which remain noncovalently linked in mature virions. Binding of the $\mathrm{S} 1$ subunit to CEACAM1 results in a conformational change of $\mathrm{S} 1$ by generation of alternative disulfide bonds. In consequence, the $\mathrm{S} 1$ fragment dissociates from S2, thereby activating the fusion activity of the viral S2 fragment [55]. The binding site on the CEACAM1a molecule is flanked by two $\mathrm{N}$-linked glycans. It was suggested that these glycans may help to delineate the region for the viral spike docking [18]. We have shown in the past that MHV strains S and JHM, which possess an HE protein, bind to Neu4,5 $\mathrm{Ac}_{2}$, presumably via the spike protein [12]. Most recently, we found that the MHV strain DVIM expresses an HE protein which is specific for $\mathrm{Neu} 5,9 \mathrm{Ac}_{2}$ [21]. It is currently unknown whether $\mathrm{N}$-glycans of murine CEACAM1a contain $O$-acetylated sialic acids. If so, the viruses might first bind to the glycans near the docking site on CEACAM1a, which then would direct the viral S1 to the docking site on CAECAM1a. In this case the first interaction between $O$-acetylated sialic acids and the viral S1 may not be essential in vitro. CEACAM1a, expressed in insect cells, was shown to bind to $\mathrm{S} 1$ and to trigger the activation of the $\mathrm{S} 2$ fusion domain. Since proteins expressed in $\mathrm{Sf} 9$ insect cells do not contain sialic acids, binding of MHV to recombinant CEACAM1a is most likely independent of the presence of $\mathrm{Neu} 4,5 \mathrm{Ac}_{2}$ or Neu5,9 $\mathrm{Ac}_{2}$.

For HIV, the receptor is the surface molecule CD4, which is sufficient for binding. Once HIV has bound to CD4, the chemokine receptors CCR5 and CXCR4 are the major coreceptors, which are required for penetration (for review: [56-58]). Compared with the situation observed for HIV, we may speculate that infection by murine coronaviruses involves at least two steps. In general terms the receptor is essential for initial binding, and additional binding to the coreceptor then allows fusion and penetration. A similar situation may exist for MHV: Depending on the virus strain, the primary receptors are either 4- or 9-O-acetylated sialic acids. 
Binding to these sugars, which we have shown to represent ligands for MHV, is the first step of infection. In order to gain entry into target cells, the viruses have then to bind to the specific coreceptor CEACAM1a. In cell culture systems with high expression rates of CEACAM1a the presence of $O$-acetylated sialic acids for infection by MHV may be not an absolute requirement. In the in vivo situation both the expression of $O$-acetylated sialic acids at the cell surface as well as the expression of HE proteins and the affinity of the viral $\mathrm{S}$ protein to $O$-acetylated sialic acids most likely determine the organ- and tissue tropism of different MHV strains. In the future it will be interesting to test this hypothesis.

Acknowledgments This work was supported by the Austrian Science Fund (Project $P$ 14104-MED).

\section{References}

1. Enjuanes, L., Brian, D.A., Cavanagh, D., Holmes, K.V., Lai, M.M.C., Laude, H., Masters, P.S., Rottier, P., Siddell, S., Spaan, W., Taguchi, F., Talbot, P.J.: Nidovirales. In: M.H.V. van Regenmortel, C.M. Fauquet, and D.H.L. Bishop (Eds.) Virus Taxonomy. Classification and Nomenclature of Viruses. Seventh report of the International Committee on Taxonomy of Viruses, (Academic Press, San Diego, 2000)

2. Drosten, C., Gunther, S., Preiser, W., Van Der Werf, S., Brodt, H.R., Becker, S., Rabenau, H., Panning, M., Kolesnikova, L., Fouchier, R.A., Berger, A., Burguiere, A.M., Cinatl, J., Eickmann, M., Escriou, N., Grywna, K., Kramme, S., Manuguerra, J.C., Muller, S., Rickerts, V., Sturmer, M., Vieth, S., Klenk, H.D., Osterhaus. A.D., Schmitz, H., Doerr, H.W.: Identification of a novel coronavirus in patients with severe acute respiratory syndrome. N. Engl. J. Med. 10, 10 (2003)

3. Ksiazek, T.G., Erdman, D., Goldsmith, C.S., Zaki, S.R., Peret, T., Emery, S., Tong, S., Urbani, C., Comer, J.A., Lim, W., Rollin, P.E., Dowell, S.F., Ling, A.E., Humphrey, C.D., Shieh, W.J., Guarner, J., Paddock, C.D., Rota, P., Fields, B., DeRisi, J., Yang, J.Y., Cox, N., Hughes, J.M., LeDuc, J.W., Bellini, W.J., Anderson, L.J.: A novel coronavirus associated with severe acute respiratory syndrome. $\mathrm{N}$. Engl. J. Med. 30, 30 (2003)

4. Marra, M.A., Jones, S.J.M., Astell, C.R., Holt, R.A., BrooksWilson, A., Butterfield, Y.S.N., Khattra, J., Asano, J.K., Barber, S.A., Chan, S.Y., Cloutier, A., Coughlin, S.M., Freeman, D., Girn, N., Griffith, O.L., Leach, S.R., Mayo, M., McDonald, H., Montgomery, S.B., Pandoh, P.K., Petrescu, A.S., Robertson, A.G., Schein, J.E., Siddiqui, A., Smailus, D.E., Stott, J.M., Yang, G.S., Plummer, F., Andonov, A., Artsob, H., Bastien, N., Bernard, K., Booth, T.F., Bowness, D., Drebot, M., Fernando, L., Flick, R., Garbutt, M., Gray, M., Grolla, A., Jones, S., Feldmann, H., Meyers, A., Kabani, A., Li, Y., Normand, S., Stroher, U., Tipples, G.A., Tyler, S., Vogrig, R., Ward, D., Watson, B., Brunham, R.C., Krajden, M., Petric, M., Skowronski, D.M., Upton, C., Roper, R.L.: The genome sequence of the sars-associated coronavirus. Science 1085953 (2003)

5. Rota, P.A., Oberste, M.S., Monroe, S.S., Nix, W.A., Campagnoli, R., Icenogle, J.P., Penaranda, S., Bankamp, B., Maher, K., Chen, M-h., Tong, S., Tamin, A., Lowe, L., Frace, M., DeRisi, J.L., Chen, Q., Wang, D., Erdman, D.D., Peret, T.C.T., Burns, C., Ksiazek, T.G., Rollin, P.E., Sanchez, A., Liffick, S., Holloway, B., Limor, J., McCaustland, K., Olsen-Rassmussen, M., Fouchier, R., Gunther, S.,
Osterhaus, A.D.M.E., Drosten, C., Pallansch, M.A., Anderson, L.J., Bellini, W.J.: Characterization of a novel coronavirus associated with severe acute respiratory syndrome. Science 1085952 (2003)

6. Snijder, E.J., Bredenbeek, P.J., Dobbe, J.C., Thiel, V., Ziebuhr, J., Poon, L.L., Guan, Y., Rozanov, M., Spaan, W.J., Gorbalenya, A.E.: Unique and conserved features of genome and proteome of SARScoronavirus, an early split-off from the coronavirus group 2 lineage. J. Mol. Biol. 331, 991-1004 (2003)

7. van der Hoek, L., Pyrc, K., Jebbink, M.F., Vermeulen-Oost, W., Berkhout, R.J., Wolthers, K.C., Wertheim-van Dillen, P.M., Kaandorp, J., Spaargaren, J., Berkhout, B.: Identification of a new human coronavirus. Nat. Med. 10, 368-73 (2004)

8. Woo, P.C., Lau, S.K., Chu, C.M., Chan, K.H., Tsoi, H.W., Huang, Y., Wong, B.H., Poon, R.W., Cai, J.J., Luk, W.K., Poon, L.L., Wong, S.S., Guan, Y., Peiris, J.S., Yuen, K.Y.: Characterization and complete genome sequence of a novel coronavirus, coronavirus HKU1, from patients with pneumonia. J. Virol 79, 884-95 (2005)

9. Regl, G., Kaser, A., Iwersen, M., Schmid, H., Kohla, G., Strobl, B., Vilas, U., Schauer, R., Vlasak, R.: The hemagglutinin-esterase of mouse hepatitis virus strain $S$ is a sialate-4- $O$-acetylesterase. J. Virol 73, 4721-7 (1999)

10. Klausegger, A., Strobl, B., Regl, G., Kaser, A., Luytjes, W., Vlasak, R.: Identification of a coronavirus hemagglutinin-esterase with a substrate specificity different from those of influenza $C$ virus and bovine coronavirus. J. Virol. 73, 3737-43 (1999)

11. Strasser, P., Unger, U., Strobl, B., Vilas, U., Vlasak, R.: Recombinant viral sialate- $O$-acetylesterases. Glycoconj. J. 20, 551-61 (2004)

12. Wurzer, W.J., Obojes, K., Vlasak, R.: The sialate-4-Oacetylesterases of coronaviruses related to mouse hepatitis virus: A proposal to reorganize group 2 Coronaviridae. J. Gen. Virol. 83, 395-402 (2002)

13. Vlasak, R., Luytjes, W., Leider, J., Spaan, W., Palese, P.: The E3 protein of bovine coronavirus is a receptor-destroying enzyme with acetylesterase activity. J. Virol. 62, 4686-90 (1988)

14. Vlasak, R., Luytjes, W., Spaan, W.: Palese P, Human and bovine coronaviruses recognize sialic acid-containing receptors similar to those of influenza $C$ viruses, Proc. Natl. Acad. Sci. USA 85, 4526-9 (1988)

15. Schultze, B., Gross, H.J., Brossmer, R., Herrler, G.: The $S$ protein of bovine coronavirus is a hemagglutinin recognizing 9- $O$ acetylated sialic acid as a receptor determinant. J. Virol. 65, 6232-7 (1991)

16. Dveksler, G.S., Pensiero, M.N., Cardellichio, C.B., Williams, R.K., Jiang, G.S., Holmes, K.V.: Dieffenbach, C.W.: Cloning of the mouse hepatitis virus (MHV) receptor: Expression in human and hamster cell lines confers susceptibility to MHV. J. Virol. 65, 6881-91 (1991)

17. Nedellec, P., Dveksler, G.S., Daniels, E., Turbide, C., Chow, B., Basile, A.A., Holmes, K.V., Beauchemin, N.: Bgp2, a new member of the carcinoembryonic antigen-related gene family, encodes an alternative receptor for mouse hepatitis viruses. J. Virol. 68, 452537 (1994)

18. Tan, K., Zelus, B.D., Meijers, R., Liu, J.H., Bergelson, J.M., Duke, N., Zhang, R., Joachimiak, A., Holmes, K.V., Wang, J.H.: Crystal structure of murine sCEACAM1a[1, 4]: a coronavirus receptor in the CEA family. Embo. J. 21, 2076-86 (2002)

19. Williams, R.K., Jiang, G.S., Holmes, K.V.: Receptor for mouse hepatitis virus is a member of the carcinoembryonic antigen family of glycoproteins. Proc. Natl. Acad. Sci. USA 88, 5533-6 (1991)

20. Herrler, G., Klenk, H.D.: The surface receptor is a major determinant of the cell tropism of influenza $C$ virus. Virology 159, 102-8 (1987)

21. Smits, S.L., Gerwig, G.J., van Vliet, A.L., Lissenberg, A., Briza, P., Kamerling, J.P., Vlasak, R., de Groot, R.J.: Nidovirus 
Sialate- $O$-Acetylesterases: Evolution and substrate specificity and substrate specificity of coronaviral and toroviral receptor-destroying enzymes. J. Biol. Chem. 280, 6933-41 (2005)

22. Iwersen, M., Vandamme-Feldhaus, V., Schauer, R.: Enzymatic 4$O$-acetylation of $\mathrm{N}$-acetylneuraminic acid in guinea-pig liver. Glycoconj. J. 15, 895-904 (1998)

23. Schauer, R., Schmid, H., Pommerencke, J., Iwersen, M., Kohla, G.: Metabolism and role of $O$-acetylated sialic acids. Adv. Exp. Med. Biol. 491, 325-42 (2001)

24. Morimoto, N., Nakano, M., Kinoshita, M., Kawabata, A., Morita, M., Oda, Y., Kuroda, R., Kakehi, K.: Specific distribution of sialic acids in animal tissues as examined by LC-ESI-MS after derivatization with 1,2-diamino-4,5- methylenedioxybenzene. Anal. Chem. 73, 5422-8 (2001)

25. Barthold, S.W., Beck, D.S., Smith, A.L.: Mouse hepatitis virus nasoencephalopathy is dependent upon virus strain and host genotype. Arch. Virol. 91, 247-56 (1986)

26. Taguchi, F., Yamada, A., Fujiwara, K.: Asymptomatic infection of mouse hepatitis virus in the rat. Brief report. Arch. Virol 59, 275-9 (1979)

27. Lavi, E., Gilden, D.H., Highkin, M.K., Weiss, S.R.: The organ tropism of mouse hepatitis virus A59 in mice is dependent on dose and route of inoculation. Lab. Anim. Sci. 36, 130-5 (1986)

28. Lavi, E., Gilden, D.H., Wroblewska, Z., Rorke, L.B., Weiss, S.R.: Experimental demyelination produced by the A59 strain of mouse hepatitis virus. Neurology 34, 597-603 (1984)

29. Homberger, F.R.: Enterotropic mouse hepatitis virus. Lab. Anim. 31, 97-115 (1997)

30. Zanetta, J.P., Pons, A., Iwersen, M., Mariller, C., Leroy, Y., Timmerman, P., Schauer, R.: Diversity of sialic acids revealed using gas chromatography/mass spectrometry of heptafluorobutyrate derivatives. Glycobiology 11, 663-76 (2001)

31. Bulai, T., Bratosin, D., Pons, A., Montreuil, J., Zanetta, J.P.: Diversity of the human erythrocyte membrane sialic acids in relation with blood groups. FEBS Lett. 534, 185-9 (2003)

32. Robbe, C., Capon, C., Maes, E., Rousset, M., Zweibaum, A., Zanetta, J.P., Michalski, J.C.: Evidence of regio-specific glycosylation in human intestinal mucins: Presence of an acidic gradient along the intestinal tract. J. Biol. Chem. 278, 46337-48 (2003)

33. Bauer, H.C., Tontsch, U.: Glial-conditioned medium and attachment to ConA are essential for long- term culture of cortical neurons, Int. J. Dev. Neurosci. 8, 151-8 (1990)

34. Sjoberg, E.R., Chammas, R., Ozawa, H., Kawashima, I., Khoo, K-H., Morris, H.R., Dell, A., Tai, T., Varki, A.: Expression of De-N-acetyl-gangliosides in Human Melanoma Cells Is Induced by Genistein or Nocodazole. J. Biol. Chem. 270, 2921-30 (1995)

35. Kamerling, J.P., Vliegenthart, J.F.G., Versluis, C., Schauer, R.: Identification of $O$-acetylated $\mathrm{N}$-acylneuraminic acids by mass spectrometry. Carbohydr Res. 41, 7-17 (1975)

36. Schauer, R., Kamerling, J.P.: Chemistry, biochemistry and biology of sialic acids, In: J. Montreuil, J.F.G. Vliegenthart, H. Schachter Glycoproteins II, (Elsevier, Amsterdam, 1997) pp. 243-402

37. Hara, S., Yamaguchi, M., Takemori, Y., Furuhata, K., Ogura, H., Nakamura, M.: Determination of mono- $O$-acetylated Nacetylneuraminic acids in human and rat sera by fluorometric highperformance liquid chromatography. Anal. Biochem. 179, 162-6 (1989)

38. Klein, A., Diaz, S., Ferreira, I., Lamblin, G., Roussel, P., Manzi, A.E.: New sialic acids from biological sources identified by a comprehensive and sensitive approach: Liquid chromatographyelectrospray ionization- mass spectrometry (LC-ESI-MS) of SIA quinoxalinones. Glycobiology 7, 421-32 (1997)
39. Kohla, G., Stockfleth, E., Schauer, R.: Gangliosides with $O$ acetylated sialic acids in tumors of neuroectocermal origin. Neurochem Res. 27, 583-92 (2002)

40. Reuter, G., Schauer, R.: Comparison of electron and chemical ionization mass spectrometry of sialic acids. Anal. Biochem. 157, 39$46(1986)$

41. Sonnino, S., Ghidoni, R., Chigorno, V., Masserini, M., Tettamanti, G.: Recognition by two-dimensional thin-layer chromatography and densitometric quantification of alkali-labile gangliosides from the brain of different animals. Anal. Biochem. 128, 104-14 (1983)

42. Zhang, G., Kurono, S., Fujita, S.C., Furuya, S., Hirabashi, Y.: Developmentally regulated $O$-acetylated sialoglycans in the central nervous system revealed by a new monoclonal antibody 493D4 recognizing a wide range of $O$-acetylated glycoconjugates. Glycobiology 14, 847-57 (1997)

43. Shi, W.X., Chammas, R., Varki, A.: Regulation of sialic acid 9-O-acetylation during the growth and differentiation of murine erythroleukemia cells. J. Biol. Chem. 271, 31517-25 (1996)

44. Tiralongo, J., Schmid, H., Thun, R., Iwersen, M., Schauer, R.: Characterisation of the enzymatic 4-O-acetylation of sialic acids in microsomes from equine submandibular glands. Glycoconj. J. 17, 849-58 (2000)

45. Iwersen, M., Dora, H., Kohla, G., Gasa, S., Schauer, R.: Solubilisation and properties of the sialate-4- $O$-acetyltransferase from guinea pig liver. Biol Chem 384, 1035-47 (2003)

46. Chou, H.H., Hayakawa, T., Diaz, S., Krings, M., Indriati, E., Leakey, M., Paabo, S., Satta, Y., Takahata, N., Varki, A.: Inactivation of CMP-N-acetylneuraminic acid hydroxylase occurred prior to brain expansion during human evolution. Proc. Natl. Acad. Sci. USA 99, 11736-41 (2002)

47. Kelm, S., Schauer, R.: Sialic acids in molecular and cellular interactions. Int. Rev. Cytol. 175, 137-240 (1997)

48. Chammas, R., Sonnenburg, J.L., Watson, N.E., Tai, T., Farquhar, M.G., Varki, N.M., Varki, A.: De-N-acetyl-gangliosides in humans: unusual subcellular distribution of a novel tumor antigen. Cancer. Res. 59, 1337-46 (1999)

49. Zhou, Q., Hakomori, S., Kitamura, K., Igarashi, Y.: GM3 directly inhibits tyrosine phosphorylation and de-N-acetyl-GM3 directly enhances serine phosphorylation of epidermal growth factor receptor, independently of receptor-receptor interaction. J. Biol. Chem. 269, 1959-65 (1994)

50. Manzi, A.E., Sjoberg, E.R., Diaz, S., Varki, A.: Biosynthesis and turnover of $O$-acetyl and $\mathrm{N}$-acetyl groups in the gangliosides of human melanoma cells. J. Biol. Chem. 265, 13091-103 (1990)

51. Cebo, C., Dambrouck, T., Maes, E., Laden, C., Strecker, G., Michalski, J.C., Zanetta, J.P.: Recombinant human interleukins IL-1alpha, IL-1beta, IL-4, IL-6, and IL-7 show different and specific calciumindependent carbohydrate-binding properties. J. Biol. Chem. 276, 5685-91 (2001)

52. Barnett, E.M., Cassell, M.D., Perlman, S.: Two neurotropic viruses, herpes simplex virus type 1 and mouse hepatitis virus, spread along different neural pathways from the main olfactory bulb. Neuroscience 57, 1007-25 (1993)

53. Hemmila, E., Turbide, C., Olson, M., Jothy, S., Holmes, K.V., Beauchemin, N.: Ceacam1a-/- mice are completely resistant to infection by murine coronavirus mouse hepatitis virus A59. J. Virol. 78, 10156-65 (2004)

54. Muchova, L., Jirsa, M., Kuroki, M., Dudkova, L., Benes, M.J., Marecek, Z., Smid, F.: Immunoaffinity isolation of CEACAM1 on hydrazide-derivatized cellulose with immobilized monoclonal anti-CEA antibody. Biomed Chromatogr 15, 418-22 (2001) 
55. Lewicki, D.N., Gallagher, T.M.: Quaternary structure of coronavirus spikes in complex with carcinoembryonic antigen-related cell adhesion molecule cellular receptors. J. Biol. Chem. 277, 19727-34 (2002)

56. Markovic, I., Clouse, K.A.: Recent advances in understanding the molecular mechanisms of HIV-1 entry and fusion: revisiting current targets and considering new options for therapeutic intervention. Curr HIV Res 2, 223-34 (2004)

57. Oppermann, M.: Chemokine receptor CCR5: insights into structure, function, and regulation. Cell Signal 16, 1201-10 (2004)

58. Philpott, S.M.: HIV-1 coreceptor usage, transmission, and disease progression. Curr. HIV Res. 1, 217-27 (2003) 